\section{Loyalitas Kreativitas \\ Aldi Masyarakat Kreatif}

P-ISSN 2722-2101, E-ISSN 2722-4201

Program Studi Ekonomi Manajemen Universitas Pamulang

Jurnal LOKABMAS Kreatif Vol.01,No.02 Juli 2020, Hal. 27-34

Email:jurnalkreatif.manajemen@gmail.com

\title{
PELATIHAN PEMASARAN SYARIAH DALAM MERAIH KEBERKAHAN PADA USAHA SANTRIWAN SANTRIWATI DI YAYASAN ALKAMILAH SAWANGAN DEPOK
}

\author{
Sugeng Samiyono, Haryono, Wiwik Hasbiyah, Khotimatus Sadiyah, Samuel Walangitan \\ Dosen Ekonomi Fakultas Ekonomi Universitas Pamulang \\ Email dosen02232@unpam.ac.id, dosen00968@unpam.ac.id, dosen01271@unpam.ac.id, \\ dosen00961@unpam.ac.id, dosen1270@unpam.ac.id
}

\begin{abstract}
ABSTRAK
Pengabdian masyarakat ini berjudul Pelatihan Pemasaran Syariah Dalam Meraih Keberkahan Pada Usaha Santriwan Santriwati Di Yayasan AlKamilah Sawangan Depok.

Tujuan pengabdian ini adalah memberikan pelatihan pemasaran syariah bagi masyarakat khususnya santriwan santriwati di yayasan AlKamilah Sawangan Depok guna meraih keberkahan. Metode pelaksanaan pengabdian ini adalah dengan Pelatihan yang dirancang untuk mengembangkan sumber daya manusia melalui rangkaian kegiatan identifikasi, pengkajian serta proses belajar yang terencana dengan 3 tahapan yaitu 1) Pengumpulan data dengan memberikan data wawancara kepada Santriwan santriwati keluhan dan kelemahan dalam memasarkan usaha secara syariah) 2). Pelatihan Pemasaran syariah dengan memberikan penyuluhan kepada Santriwan santriwati di yayasan Alkamilah. 3) Memberikan pendampingan Pelatihan pemasaran syariah dengan memberikan pelatihan kepada Santriwan santriwati di yayasan Alkamilah. Untuk mendukung hal itu diperlukan sebuah rencana kegiatan diantaranya adalah tahap persiapan yaitu dengan menyiapkan semua peralatan yang dibutuhkan untuk melaksanan kegiatan pkm, studi literatur dan melakukan koordinasi dengan instansi lembaga yayasan terkait serta ketua yayasan khususnya. Tahap enentuan Lokasi, yaitu dengan melakukan kunjungan ke lokasi untuk menentukan tempat pendampingan dan pelatihan pemasaran syariah. Tahap Perancangan implemnetasi dan pengawasan melalui pelatihan pemasaran syariah yang dilakukan oleh 5 orang dosen pada usaha dagang santriwan santriwati di yayasan Alkamilah sawangan depok.

Kesimpulan dari pengabdian ini adalah peserta pengabdian sangat antusias terhadap pelatihan, hal ini ditunjukan dengan banyaknya antusiasme pertanyaan tentang proses pemasaran syariah dalam rangka mendukung aktifitas kegiatan usaha yang telah berjalan di yayasan Alkamilah baik melalui system kerjasama maupun system usaha mandiri.
\end{abstract}

\section{Kata Kunci: Pemasaran Syariah, Berkah, Bauran Pemasaran}

\section{ABSTRAC}

This community service is titled Sharia Marketing Training in Achieving Blessing in Santriwan Santriwati's Business at the AlKamilah Sawangan Foundation in Depok.

The purpose of this service is to provide training in sharia marketing to the community, especially female students at the AlKamilah Sawangan Depok foundation in order to achieve blessings. The method of implementing this dedication is through training designed to develop human resources through a series of planned identification, assessment and learning processes with 3 stages, namely 1) Data collection by giving interview data to Santriwan santriwati complaints and weaknesses in sharia 


\section{Loyalitas Kreativitas \\ Aldi Masyarakat Kreatif}

P-ISSN 2722-2101, E-ISSN 2722-4201

Program Studi Ekonomi Manajemen Universitas Pamulang

Jurnal LOKABMAS Kreatif Vol.01,No.02 Juli 2020, Hal. 27-34

Email:jurnalkreatif.manajemen@gmail.com

business marketing) 2 ). Sharia Marketing Training by providing counseling to Santriwan santriwati at the Al-Kamilah foundation. 3) Providing mentoring Sharia marketing training by providing training to Santriwan santriwati at the alkamilah foundation. To support this, a plan of activities is needed, including the preparation stage, which is by preparing all the equipment needed to carry out the pkm activities, studying literature and coordinating with related institutions and the chairperson of the foundation in particular. Location Determination Phase, namely by visiting the location to determine the place of assistance and training in sharia marketing. Design phase of implementation and supervision through Sharia marketing training conducted by 5 lecturers in the trade business of female students at the Alkamilah Foundation in Depok

The conclusion of this dedication is that the participants are very enthusiastic about the training, this is shown by the many enthusiasm questions about the sharia marketing process in order to support the business activities that have been running at the Alkamilah foundation both through a system of cooperation and an independent business system.

\section{Keywords: Sharia Marketing, Blessing, Marketing Mix}

\section{PENDAHULUAN}

Pemasaran menarik perhatian yang sangat besar baik dari perusahaan, lembaga maupun antar bangsa. Berbagai organisasi dalam melaksanakan pemasaran seperti lembaga pemerintah, orgnisasi keagamaan dan lain-lain memandang pemasaran sebagai suatu cara baru untuk berhubungan dengan masyarakat umum. Pada umumnya pemasaran dianggap sebagi tempat bagi para penggeruk keuntungan, orang penuh muslihat, penjaja barang yang menggoda keinginan orang. Oleh sebab itu banyak konsumen yang ditelan oleh orang-orang jahat, tapi apabila kita menerapkan sistem islam di pemasaran itu maka hal-hal seperti itu tidak akan terjadi. Pada dasarnya, bagi umat islam Nabi Muhammad SAW telah mengajarkan kepada kita bagaimana sistem pemasaran islami. Akan tetapi, karena di masyarakat sudah berakar sistem pemasaran konvensional maka sistem pemasaran islam kurang dikenal. Hal ini juga menjadi pelajaran untuk kita agar dapat mengenalkan kembali dan menjadikan sistem pemasaran syariah berkembang kembali di kalangan masyarakat guna mengatur seluruh aspek kehidupan salah satunya aspek bisnis seperti perdagangan, industri, perbankan, asuransi, utang-piutang, pemasaran, hibah. Aspek ekonomi seperti permodalan, zakat, baitul Maal, fa'i, ghanimah.

Saat ini, telah berdiri sebuah yayasan sosial di Jl. Serua Raya No.3, Serua, Kec.
Bojongsari, Kota Depok. Yayasan ini bernama AlKamilah, yayasan ini berdiri sejak 30 Oktober 2012 yang telah mampu menampung 30 anak asuh di asrama depok. Sedangkan 50 anak diantaranya berada Kebumen, Purwakarta, Banten.

Untuk aspek pengembangan dan inovasi program, Yayasan Al Kamilah ingin maju tanpa ketergantungan dengan donatur. Sehingga, setiap ada bantuan dari para pendiri dan donatur, yayasan tersebut menyisihkan untuk membentuk usaha. Salah satu usahanya adalah membuat keripik pisang yang sudah berjalan sejak Desember 2017. Keripik pisang ini dapat terjual sekitar 200 bungkus dengan harga perkemasan Rp 10.000-Rp.20.000. Namun, usaha tersebut bukan tanpa rintangan. Berdasarkan wawancara dengan pihak yayasan Bpk Haryono, kendala yang dihadapi saat ini adalah permodalan dan komuditinya, yakni pisang kepok super yang berasal dari Lampung, dimana stoknya terbatas. Permasalahan lainnya adalah SDM dan pelatihan bagi karyawan baru terhadap produk usaha yang dijalankan pihak yayasan Alkamilah..

Melihat permasalahan tersebut, sangatlah penting memberikan pelatihan pemasaran syariah bagi masyarakat dalam kehidupan sehari-hari khususnya santriwan santriwatidi yayasan Alkamilah, sekaligus sebagai wujud Tri Darma Perguruan Tinggi, Fakultas Ekonomi S1 UNPAM , maka 
diselenggarakanlah kegiatan pengabdian kepada masyarakat dengan judul "Pelatihan Pemasaran Syariah Dalam Meraih Keberkahan Pada Usaha Santriwan Santriwati Di Yayasan AlKamilah Sawangan Depok"

\section{RUMUSAN MASALAH}

Dengan memperhatikan latar belakang yang telah dipaparkan diatas perumusan masalah pada PKM ini adalah :

1) Bagaimana memberikan pemahaman pemasaran syariah dalam memasarkan usaha santriwan dan santriwati ?

2) Bagaimana memberikan wawasan pemasaran syariah pada santriwan santriwati di yayasan Alkamilah?

3) Bagaiaman mengimplementasi pemasaran syariah dalam menjual usaha santriwan santriwati pada masyarakat umum ?

\section{TUJUAN PELAKSANAAN}

1) Membantu Santriwan dan Santriwati di yayasan Alkamilah dalam memahami pemasaran syariah

2) Memberikan Wawasan kepada Santriwan Santriwati di yayasan Alkamilah tentang Bagaimana meraih keberkahan pada Usaha bisnis.

3) Memberikan pelatihan dengan mengimplementasikan pemasaran syariah dalam menentukan Strategi Bisnis untuk meraih keberkahan dalam kehidupan

\section{TINJAUAN PUSTAKA}

\section{Pemasaran Syariah}

Pemasaran adalah bentuk muamalah yang dibenarkan dalam Islam, sepanjang dalam segala proses transaksinya terpelihara dari hal-hal terlarang oleh ketentuan syariah.Seperti:kebutuhan, keinginan dan permintaan produk-produk (barang, layanan, dan ide), value, biaya dan kepuasan, pertukaran dan transaksi, hubungan dan jaringan, pasar dan pemasar serta prospek. Ini artinya bahwa dalam syariah marketing, seluruh proses, baik proses penciptaan, proses penawaran, maupun proses perubahan nilai (value), tidak boleh ada hal-hal yang bertentangan dengan akad dan prinsip-prinsip muamalah yang Islami. Pemasaran dapat dibolehkan, dalam kaidah fiqh dikatakan, al muslimuuna ala syurutihim illa syarthan harrama halalan aw ahalla haraman (kaum muslimin terikat dengan kesepakatankesepakatan bisnis yang mereka buat, kecuali kesepakatan yang mengharamkan yang halal.

Ada 4 karakteristik syariah marketing yang dapat menjadi panduan bagi para pemasar sebagai berikut:

a. Teistis (rabbaniyyah) : jiwa seorang syariah marketer meyakini bahwa hukum-hukum syariat yang teistis atau bersifat ketuhanan ini adalah yang paling adil, paling sempurna, paling selaras dengan segala bentuk kebaikan, paling dapat mencegah segala bentuk kerusakan, paling mampu mewujudkan kebenaran, memusnahkan kebatilan dan menyebarluaskan kemaslahatan.

b. Etis (akhlaqiyyah) : Keistimewaan lain dari syariah marketer selain karena teistis ( rabbaniyyah) juga karena ia sangat mengedepankan masalah akhlak (moral, etika) dalam seluruh aspek kegiatannya, karena nilai-nilai moral dan etika adalah nilai yang bersifat universal, yang diajarkan oleh agama.

c. Realistis (al-waqiyyah) : syariah marketer adalah konsep pemasaran yang fleksibel, sebagaimana keluasan dan keluwesan syariah islamiyah yang melandasinya. Syariah marketer adalah para pemasar professional dengan penampilan yang bersih, rapi dan bersahaja, apapun model atau gaya berpakaian yang dikenakannya, bekerja dengan mengedepankan nilai-nilai religius, kesalehan, aspek moral dan kejujuran dalan segala aktivitas pemasarannya..

d. Humanistis (insaniyyah) : keistimewaan syariah marketer yang lain adalah sifatnya 
yang humanistis universal, yaitu bahwa syariah diciptakan untuk manusia agar derajatnya terangkat, sifat kemanusiaannya terjaga dan terpelihara, serta sifat-sifat kehewanannya dapat terkekang dengan panduan syariah. Syariat Islam diciptakan untuk manusia sesuai dengan kapasitasnya tanpa menghiraukan ras, jenis kelamin, warna kulit, kebangsaan dan status. Hal inilah yang membuat syariah memiliki sifat universal sehingga menjadi syariah humanistis universal.

Dalam syariah marketing, bisnis yang disertai dengan keikhlasan semata-mata hanya untuk mencari keridhaan Allah, maka seluruh bentuk transaksinya insya Allah menjadi ibadah di hadapan Allah SWT. Ini akan menjadi bibit dan modal dasar untuk tumbuh menjadi bisnis yang besar, yang memiliki spiritual brand, yang memiliki kharisma, keunggulan, dan keunikan yang tak tertandingi. Dalam spiritual marketing, hal-hal yang sekiranya dapat merugikan konsumen akan berusaha untuk dihindarkan. Kejutan besar dilakukan Stephen R Covey dimana dia telah menerbitkan buku baru yang menambahkan dari "The 7 Habit of Highly Effective People" menjadi "The 8th Habit: From Effectiveness to Greatness. Covey akhirnya berkesimpulan bahwa faktor spiritual merupakan faktor kunci terakhir yang harus dimiliki seorang pemimpin dalam suatu perusahaan, ia menyebutnya dengan "Voice". Seorang pemimpin harus memiliki empat style, "The 4 Roles of Leadership" yaitu "Pathfinding (perintisan), Aligning (penyelerasan), Empowering (pemberdayaan), dan Modeling (panutan). Pada bagian akhir inilah Covey kemudian menyadari bahwa untuk menjadi seorang pemimpin yang bisa jadi panutan, seorang pemimpin haruslah memimpin berdasarkan prinsip. Pemimpin harus mampu menyatukan apa yang diucapkan dengan perbuatan dan pemimpin adalah seseorang yang layak dipercaya. Kata kunci untuk semua ini adalah kejujuran yang senantiasa menjadi bagian dari nilai-nilai spiritual

\section{Tujuan dan Fungsi Pemasaran Syariah}

Tujuan dan fungsi pemasaran islami (syariah) Menurut Hermawan Kertajaya dan Muhammad Syakir Sula adalah memberikan dua tujuan utama dari marketing syariah atau pemasaran syariah, yaitu:

a) Me-marketing-kan Syariah dimana perusahaan yang pengelolaannya berlandaskan syariah Islam dituntut untuk bisa bekerja dan bersikap profesional dalam dunia bisnis. Juga dibutuhkan suatu program pemasaran yang komprehensif mengenai nilai dan value dari produk- produk syariah agar dapat diterima dengan baik, sehingga tingkat pemahaman masyarakat yang masih memandang rendah terhadap perbedaaan yang ditawarkan oleh perusahaan yang berbasiskan islami.

b) Me-marketing-kan dengan mensyariahkan marketing, adalah sebuah teknik pemasaran tidak akan serta merta menjalankan bisnisnya demi keuntungan pribadi saja tetapi juga karena usaha untuk menciptakan dan menawarkan bahkan dapat merubah suatu nilai kepada para penguasa utamanya (Allah Swt, konsumen, karyawan, pemegang saham). Sehingga usaha tersebut dapat menjaga keseimbangan laju bisnisnya dan menjadi bisnis yang berkelanjutan yang sessuai dengan konsep Islami atau Syariah.

\section{Strategi Pemasaran Syariah}

Dalam dunia bisnis, pemasaran merupakan strategi bisnis yang mengarahkan proses penciptaan, penawaran, dan perubahan nilai dari seorang inisiator kepada pelanggannya. Menurut ajaran Islam, kegiatan pemasar harus dilandasi dengan nilai-nilai islami yang dijiwai oleh semangat ibadah kepada Allah dan berusaha semaksimal mungkin kesejahteraan bersama. Menurut prinsip syariah, kegiatan pemasaran harus dilandasi semangat beribadah kepada Tuhan Sang Maha Pencipta, berusaha semaksimal mungkin untuk kesejahteraan bersama, 
bukan untuk kepentingan golongan apalagi kepentingan sendiri. Istilah pemasaram tidak banyak dikenal pada masa Nabi. Saat itu konsep yang banyak dikenal adalah jual beli (bay') yang memang sudah ada sebelum islam datang. Pemasaran dapat dilakukan melalui komunikasi dan silahturahmi dalam rangka untuk memperkenalkan produk atau barang dagangan. Dalam Hadis Nabi dari Anas ibn Malik yang diriwayarkan oleh al-bukhari dan muslim : "Barangsiapa ingin agar rezekinya dilapangkan dan pengaruhnya diluaskan maka hendaknya ia menyambung tali silahtuhrami". Dari hadist tersebut dapat disimpulkan bahwa dalam kegiatan pemasaran juga melakukan silahtuhrami sesama manusia. Menjaga silahturahmi sesama manusia adalah hal yang wajib. Karena dalam pemasaran tentunya akan bertemu dengan orang banyak, semakin banyak relasi yang dikenal akan semakin memperpanjang tali silahturahmi. Maka dari itu sebaiknya senantiasa untuk selalu menjaga tali silahturahmi sesama manusia. Dalam sebuah hadits disebutkan : "Ibnu Umar berkata: Seorang laki-laki mengadu pada Nabi, "Aku telah tertipu dalam jual beli." Maka beliau bersabda, "Katakanlah kepada orang yang kamu ajak berjual beli, "Tidak boleh menipu!" Sejak itu, jika ia bertransaksi jual beli, ia mengatakannya. (HR. Bukhari). Hadits tersebut dapat menjadi acuan bagi upaya promosi yang dilakukan oleh perusahaan baik dalam hal menjual produk atau jasa ke publik agar memberikan informasi yang benar dan akurat, sehingga tidak mengandung unsur penipuan yang dapat merugian konsumen atau pelanggan.

\section{METODE PELAKSANAAN}

Metodepelaksanaan pengabdian ini dilakukan dalam beberapa kegiatan yaitu:

a. Metode Pelatihan

Metode pelaksanaan pengabdian ini adalah dengan Pelatihan yang dirancang untuk mengembangkan sumber daya manusia melalui rangkaian kegiatan identifikasi, pengkajian serta proses belajar yang terencana dengan 3 tahapan yaitu hari ke-1 Pengumpulan data dengan memberikan data wawancara kepada Santriwan santriwati keluhan dan kelemahan dalam memasarkan usaha secara syariah) hari ke-2: Pelatihan Pemasaran syariah dengan memberikan penyuluhan kepada Santriwan santriwati di yayasan Al-kamilah. Hari ke-3 Memberikan pendampingan Pelatihan pemasaran syariah dengan memberikan pelatihan kepada Santriwan santriwati di yayasan alkamilah.

b. Rencana Kegiatan

1. Tahap persiapan, Persiapan ini difokuskan dengan menyiapkan semua peralatan yang dibutuhkan untuk melaksanan kegiatan ini, studi literatur dan melakukan koordinasi dengan instansi lembaga yayasan terkait serta ketua yayasan khususnya dan pada santriwan santriwati untuk melakukan kegiatan pelatihan pemasaran syariah dalam meraih keberkahan pada usaha santriwan santriwati di yayasan al kamilah.

2. Penentuan Lokasi, Pada tahap ini dilakukan kunjungan ke lokasi untuk menentukan tempat (lokasi) pendampingan serta pelatihan Pemasaran syariah dalam meraih keberkahan pada usaha santriwan santriwati di yayasan alkamilah sawangan depok

3. Perancangan implemnetasi dan pengawasan dalam pelatihan pemasaran syariah pada usaha santriwan santriwati di yayasan Alkamilah sawngan depok.

c. Prosedur Kerja

1. Tahap persiapan, meliputi Survei awal. Pada tahap ini dilakukan survei lokasi Yayasan Al Kamilah di Desa Serua, Kec. Sawangan, Kab. Depok.

2. Observasi. Setelah survei maka ditentukan pelaksanaan dan sasaran peserta kegiatan

3. Rapat Koordinasi Tim. Pada tahap ini rapat mengenai pembagian tugas, membuat jadwal pelaksanaan, mulai dari persiapan, pelaksanaan, sampai evaluasi dan penyusunan laporan.

d. Tahap Pelaksanaan 


\section{Loyalitas Kreativitas \\ Aldi Masyarakat Kreatif}

P-ISSN 2722-2101, E-ISSN 2722-4201

Program Studi Ekonomi Manajemen Universitas Pamulang

Jurnal LOKABMAS Kreatif Vol.01,No.02 Juli 2020, Hal. 27-34

Email:jurnalkreatif.manajemen@gmail.com
1. Sosialisasi Program. Pada tahap awal pelaksanaan dilakukan sosialisasi program pemasaran syariah kepada calon mitra Usaha santriwan dan santriwati yayasan Alkamilah sawangan depok.

2. Pelatihan/Pendampingan. Sesuai dengan langkah selanjutnya adalah memberikan pelatihan/ pendampingan berupa pelatihan Pemasaran syariah pada usaha bisnis santriwan santriwati yayasan Alkamilah

e. Tahap evaluasi..

Tahap evaluasi merupakan penilaian setelah rangkaian kegiatan dilakukan oleh pelaksana sesuai dengan jadwal yang telah ditentukan. Evaluasi ini berupa perbaikan atau saran untuk pelaksanaan kegiatan lebih baik lagi.

\section{HASIL DAN PEMBAHASAN}

Pengabdian Masyarakat (LPPM) Universitas Pamulang yang dilakukan oleh dosen-dosen program studi Manajemen telah berjalan dengan lancar dan mendapat sambutan hangat dari tempat pelaksanaan kegiatan ini. Partisipasi mitra dalam pelaksanaan program PKM ini sangat kooperatif dengan memberikan ijin kepada tim untuk melaksanakan pengabdian masyarakat khususnya pada santriwan santriwati, memberikan keterangan baik berupa informasi atau data-data yang dibutuhkan sampai rencana pelaksanaan berupa kegiatan pelatihan/pendampingan nantinya.

\section{A. Materi PKM}

1) Hukum dalam bermualamah Bertransaksi dalam berbisnis:

a. Dengan ketentuan seperti inilah maka aturan muamalah dalam Islam menjadi sangat fleksibel sehingga Islam dapat terus berkembang dan relevan sesuai dengan perkembangan waktu dan tempat.

2) Identifikasi transaksi yang terlarang dalam sayariah:

a. Haram obyek yang di transaksikan

b. Haram cara transaksi-nya

c. Tidak sah/lengkap akad transaksi-nya

3. Obyek Transaksi yang Terlarang:
a. Barang/jasa
yang secara

diharamkan b. Barang yang serupa/analog dengan yang diharamkan

c. Tidak memenuhi kaidah-kaidah syariat Islam

3) Cara-Cara Pengembangan Harta yang Terlarang:

a. Melanggar Prinsip "An Taradin Minkum"

b. Melanggar Prinsip "La Tazhlimunawala Tuzhlamun"

4) Tidak Sah/Lengkap Akad Transaksi-nya:
a. Rukun dan syarat akad tidak terpenuhi
b. Ta'alluq
c. Shafqatain fi al-shafqah

5) Pelarangan Riba dalam Al Quran:
a. Ar Rum ayat 39
b. An Nisa ayat 160-161
c. Ali Imran ayat 130
d. Al Baqarah 275-281

B. Kegiatan PKM di yayasan Alkamilah yaitu:

\begin{tabular}{|l|l|}
\hline \multicolumn{1}{|c|}{ Acara } & \multicolumn{1}{c|}{ Koordinator } \\
\hline Pembukaan & Khotimatus Sadiyah \\
\hline Sambutan1 & $\begin{array}{l}\text { Sugeng Samiyono } \\
\text { (Unpam) }\end{array}$ \\
\hline Sambutan2 & Haryono(AlKamilah) \\
\hline $\begin{array}{l}\text { Materi1 } \\
\text { Bisnis syraiah }\end{array}$ & Samuel \\
\hline $\begin{array}{l}\text { Materi2 } \\
\text { Pemasaran } \\
\text { Syariah }\end{array}$ & Wiwikhasbiyah \\
\hline Penutup & Khotimatus Sadiyah \\
\hline
\end{tabular}

Harapan kami melalui pengabdian ini dapat menambah keilmuan bagi santriwan santriwati yayasan Alkamilah dalam mengenal pemasaran syariah dan bisnis syariah.

\section{KESIMPULAN DAN SARAN \\ Kesimpulan}

Peserta pengabdian sangat antusias terhadap pelatihan, hal ini ditunjukan dengan banyaknya antusiasme pertanyaan tentang proses pemasaran syariah dalam rangka mendukung aktifitas kegiatan usaha yang telah berjalan di yayasan Alkamilah baik melalui sistem kerjasama maupun sistem usaha mandiri. 


\section{Loyalitas Kreativitas \\ Aldi Masyarakat Kreatif}

P-ISSN 2722-2101, E-ISSN 2722-4201

Program Studi Ekonomi Manajemen Universitas Pamulang Jurnal LOKABMAS Kreatif Vol.01,No.02 Juli 2020, Hal. 27-34 Email:jurnalkreatif.manajemen@gmail.com
Saran

Sebaiknya program kegiatan pengabdian kepada masyarakat (PKM) ini dapat dilakukan secara berkelanjutan agar ada kesinambungan antara program yang satu dengan yang lainnya.Dengan adanya kesinambungan diharapkan santriwan santriwati dapat menjadi wirausaha unggul dalam memasarkan produk usaha yaysan di masa yang akan dating.

\section{DAFTAR PUSTAKA}

Abbas salim, Asuransi dan manajemen resiko,Grafindo Persada,Jakarta, 2000.

Ali Mustafa ya'qub. Pengelolaaan dana asuransi syariah, 2001.

AMMAI, buku panduan Ujian Gelar Profesional keanggotaan asosiasi ahli manajemen asuransi Indonesia, sector jiwa, AMMAI, 2000

Arthur andersen ,Islamic Banking-Market study, 1999

Budi Wisakseno, Rasionalitas Nasabah Perbankan Syariah, republika, Jumat, 23 Change , Harvard Business Scool Press

Didin Hafidhuddin \& Hendri Tanjung, Manajemen Syariah Dalam Praktek.

Direktorat Perbankan Syariah Bank Indonesia, Stasitistik perbankan syariah, Agustus 2016

Encyclopedia Brittanica, X, (Micropeadia)). H. 49. Dikutip dari Hermawan Kartajaya, Gema Insani, 2003

Hermawan Kartajaya, Aa Gym: A Spritual Marketer. Mark Plus \& Co., 2005 Hermawan Kartajaya, Hermawan Kartajaya On Marketing, Gramedia, Jakarta 2002

Jurnal Khatulistiwa - Journal Of Islamic Studies Volume 4 Nomor 1 Maret 2014 Kasmir, pemasaran bank, edisi revisi, Jakarta: Kencana prenada media group, $2008 \mathrm{M}$. Nur Rianto Al Arif. Dasar-dasar Pemasaran Bank Syariah, Alpabeta Bandung, Majalah SWA No. 22/xxi/249 November 2005
Muhammad Sula dan Hermawan Kertajaya. Syariah Marketing, Jakarta. Mizan. 2005

Muhammad, Managemen Bank Syari'ah, edisi revisi cet. ke-2, Yogyakarta: UPP STIM YKPN, 2011 Pebruari 2005

Purnama Putra, Wiwik hasbiyah. Teori dan praktik Pemasaran syariah, Ed.1 cet. 1, Depok.

Pasaribu, V. L. D., Agrasadya, A., Shabrina, N., \& Krisnaldy, K. (2020). MENJADI ENTERPRENEUR MUDA YANG MEMILIKI JIWA LEADERSHIP UNTUK MENGHADAPI MASA DEPAN. Abdi Laksana, 1(1)

Pasaribu, V. L. D., Elburdah, R. P., Sudarso, E., \& Fauziah, G. (2020). PENGGUNAAN MANAJEMEN WAKTU TERHADAP PENINGKATAN PRESTASI BELAJAR DI SMP ARAISIYAH. Jurnal ABDIMAS, 1(1)

Pasaribu, V. L. D., Susanti, F., \& Hartuti, E. T. K. (2019). MEMOTIVASI SISWA DAN SISWI SMK LETRIS INDONESIA DI DALAM MENENTUKAN PILIHAN UNTUK MELANJUTKAN PENDIDIKAN ATAU BEKERJA SETELAH LULUS

SEKOLAH. Jurnal Pengabdian Dharma

Laksana, 1(2), 161-172.

Pasaribu, V. L. D., Oktrima, B., Prabowo, B., Arianto, N., \& Haryoko, U. B. (2020). PROGAM PENDAMPINGAN DAN PENYELENGGARAAN PENDIDIKAN ANAK PADA USIA DINI TERHADAP PRESTASI BELAJAR DILINGKUNGAN RT 020 RW 009. KEL GIRI PENI. KEC WATES. YOGYAKARTA. JURNAL LOKABMAS KREATIF, 1(1), 71-75.

Pasaribu, V. L. D., Sulaiman, S., Sutiman, S., Thaharudin, T., \& Purnomo, B. Y. (2020).

PENGENALAN LETAK POSYANDU TERDEKAT DIKELURAHAN PISANGAN DENGAN MANAJEMEN PEMASARAN REVOLUSI 4.0 UNTUK MENINGKATKAN PENGETAHUAN MASYARAKAT LETAK DAN FUNGSI POSYANDU TERDEKAT PADA KELURAHAN PISANGAN. DEDIKASI PKM, 1(1), 105-110.

Pasaribu, V. L. D., \& Krisnaldy, K. (2019). Manajemen Risiko dan Asuransi. 
Loyalitas Kreativitas

Aldi Masyarakat Kreatif
P-ISSN 2722-2101, E-ISSN 2722-4201

Program Studi Ekonomi Manajemen Universitas Pamulang Jurnal LOKABMAS Kreatif Vol.01,No.02 Juli 2020, Hal. 27-34 Email:jurnalkreatif.manajemen@gmail.com

\section{DOKUMENTASI FOTO KEGIATAN}
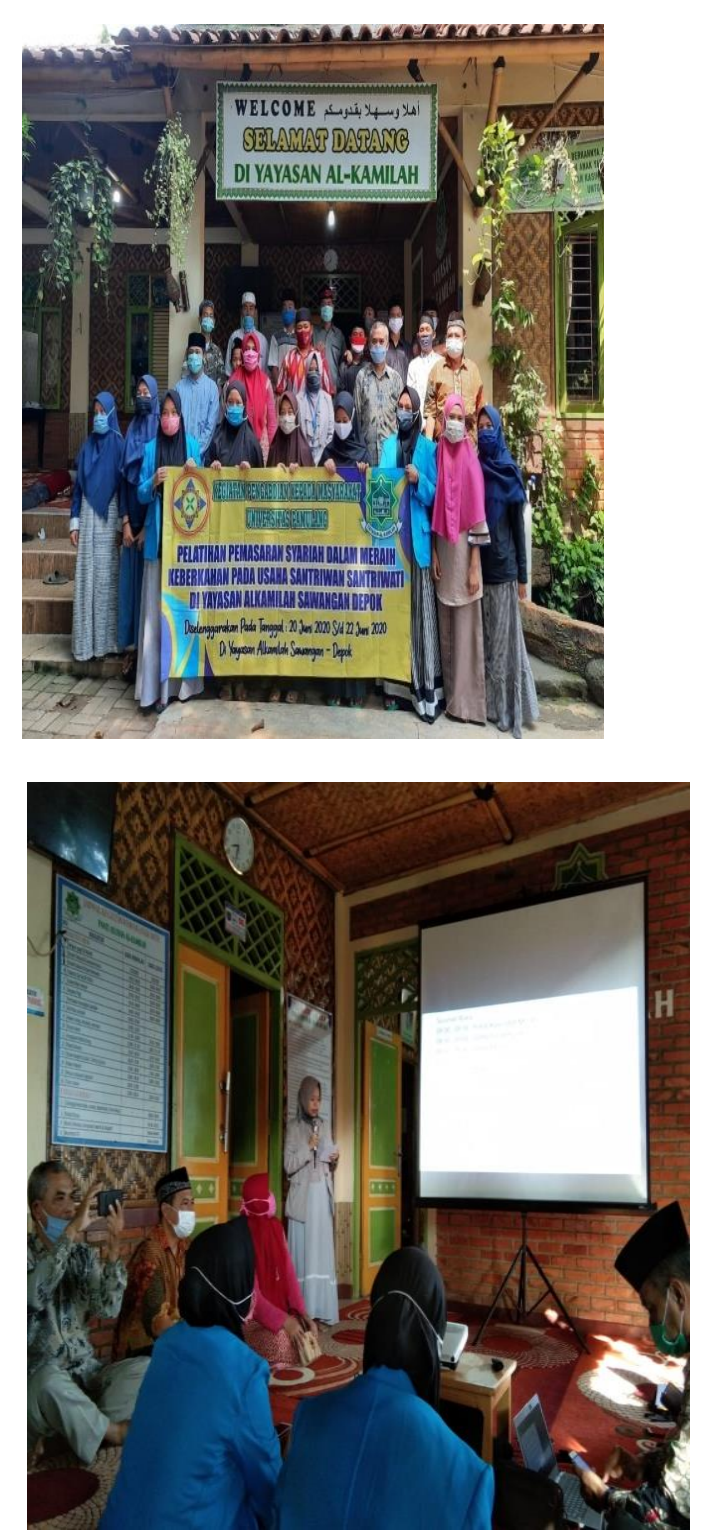
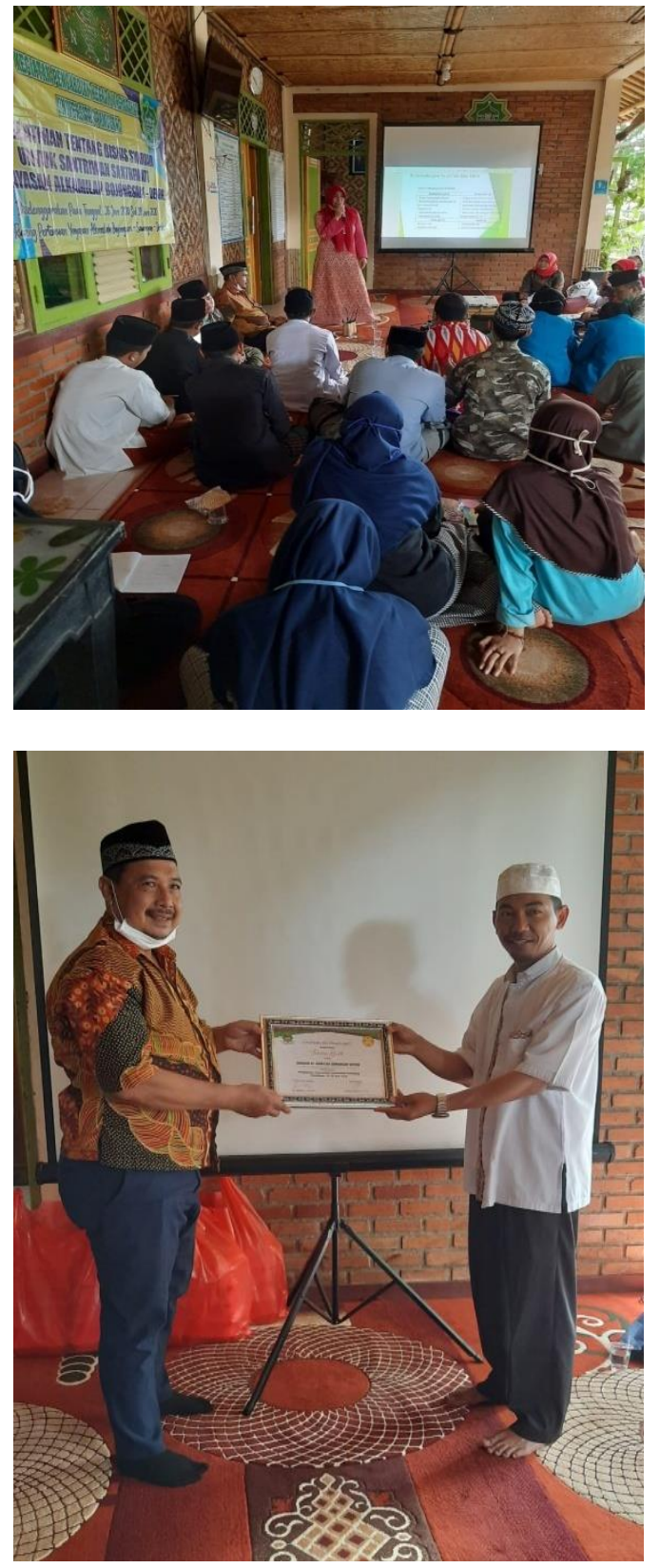